\title{
Genetic Diversity and Comprehensive Phylodynamic analysis of whole Corona Viruses Genomes
}

\section{Shehla Javaid, Hina Awais}

University Institute of Medical Lab Technology, University of Lahore, Lahore, Pakistan.

Corresponding to: Ms. Shehla Javaid, Email: shehla.javaid@mlt.uol.edu.pk, ORCiD: 0000-0001-5672-5148

\begin{abstract}
Covid-19 is a rapidly emerging viral respiratory disease. The infection of corona virus disease (COVID-19) is initiated by the strains of severe acute respiratory syndrome. Corona virus 2 (SARS-CoV-2), is a highly transmittable viral infection that was first emerged in the of Wuhan, a city of China and ultimately extent in whole world. The World health organization (WHO) affirmed this infection as a global public health disaster. Genomic analysis showing that this novel SARSCoV-2 is hereditarily linked with severe acute respiratory syndrome-like (SARS-like) bat viruses indicating that bats might be the primary source of this epidemic infection. In this review we have summarized a comprehensive phylodynamic analysis of whole corona virus genome sequences in order to analyze the pathogenicity and emergence of novel COVID-19 infection and previous human coronaviruses. Our main objective is to describe the genetic relationships of the 2019-nCoV with other genera of coronavirus and to find out supposed recombination contained by sarbecovirus subgenus.
\end{abstract}

Keywords: COVID-19, Phylogeny, SARS-CoV, MERS-CoV, Coding Sequence (CDS).

This is an Open Access article distributed under the terms of the Creative Commons Attribution Non-Commercial License (http:// creative commons. org/licenses/by-nc/4.0) which permits unrestricted non-commercial use, distribution, and reproduction in any medium, provided the original work is properly cited.

\section{INTRODUCTION}

Evolution is a vibrant and constant interchange, where hosts and pathogens are in nonstop fight to overwhelm one another. Irregular changes in pathogens genome at that point etched by normal choice enable them to accomplish expanded harmfulness and mechanisms to avoid host immune reaction. The recent outbreak of COVID-19 is another expression of natural selection.' Coronavirus two strains named as MERS-CoV and SARSCoV infect humans but comparatively at narrow scale. ${ }^{2}$ A new strain of Coronavirus (as shown in figure 1) also known as 2019 novel coronavirus or COVID-19 caused the recent outbreak of pneumonia that was first time detected in the Wuhan City of China..5 The COVID-19 brought about by extreme intense respiratory disorder that has a community healthiness Crisis of global apprehension, representing a genuine danger to individuals' wellbeing just as the clinical and overall health framework. ${ }^{6}$ It was observed that this outbreak was closely associated with sea food and local animal market. Scientists are progressing to decide the ancestries of the infection. Until this point in time, a large number of human diseases have been affirmed in China alongside many sent out cases over the globe.?

Gastrointestinal tract infections and respiratory infections are mainly caused by coronaviruses. Corona viruses didn't pull in around the world consideration until unless the 2003 SARS epidemic, afterward the MERS (Middle East Respiratory Syndrome) in 2012 and now the recent most of COVID-19 wave in China. ${ }^{8}$ MERS$\mathrm{COV}$ or SARS-CoV are highly pathogenic and can target respiratory tract and central nervous system of human causing multiple organ failure. The two of them SARS$\mathrm{COV}$ and MERS-COV have their route of transmission from bats to palm jaguar or camels and ultimately to human being. , $^{10}$

\section{Genetic Characterization of COVID-19}

Genetically this virus belongs to a genus Coronaviridae. The Coronaviridae consists of two subfamilies Torovirinae and Coronavirinae. The former is auxiliary categorized into IV foremost genera including Alpha coronavirus ( $\alpha-\mathrm{CoV})$, Beta coronavirus ( $\beta-\mathrm{CoV})$, Gamma coronavirus $(\gamma-\mathrm{CoV})$, and Delta coronavirus $(\delta-\mathrm{CoV}) .{ }^{1 "}$ Mammals are primarily effected by $1^{\text {st }}$ two genera while birds are predominantly effected by latter two genera. Previously VI different types of Coronaviruses have been recognized. The viruses that belongs to genus Alpha coronavirus are HCoV-229E and HCoV-NL63 while that belongs to Beta coronavirus genus are MERS-CoV and SARS-CoV, HCOVHKU1 and HCOV-OC43. ${ }^{12}$

Until now lot of different studies proposed that the coronaviruses linear single stranded RNA genome ranges in size from $26 \mathrm{k}$ to $32 \mathrm{~K}$ bases and considered as a biggest genome amongst RNA enveloped viruses and includes an open reading frame (ORFs) of variable 
number i.e. from 6-11). ${ }^{13-17}$ The primary open reading frame (ORF) of COVID 19 consists of almost sixty seven percent of whole genome and encoded the sequence of sixteen proteins that are non-structural in nature. While the organizational and accessory proteins are set by lasting ORFs. ${ }^{18}$ So, the most important IV organizational proteins includes matrix protein $(M)$, small envelope protein (E), nucleocapsid protein $(\mathrm{N})$ and spike surface glycoprotein (S). On the host cell these spike surface glycoproteins have a crucial role in receptors binding and determining the host response against stimuli. ${ }^{19}$ MERS-COV and SARS-CoV spike proteins have different receptor binding domains that bind to host receptors. One of the main receptor for COVID-19 is angiotensin-converting enzyme 2 (ACE2) while CD209L use as an alternate. ${ }^{20}$ On the other hand di-peptidyl peptidase four (DPP4), furthermore identified as CD26 which is used as a prime receptor by MERS-CoV. Nonetheless, up until this point, there are still debates about the virus source and its intermediary host.

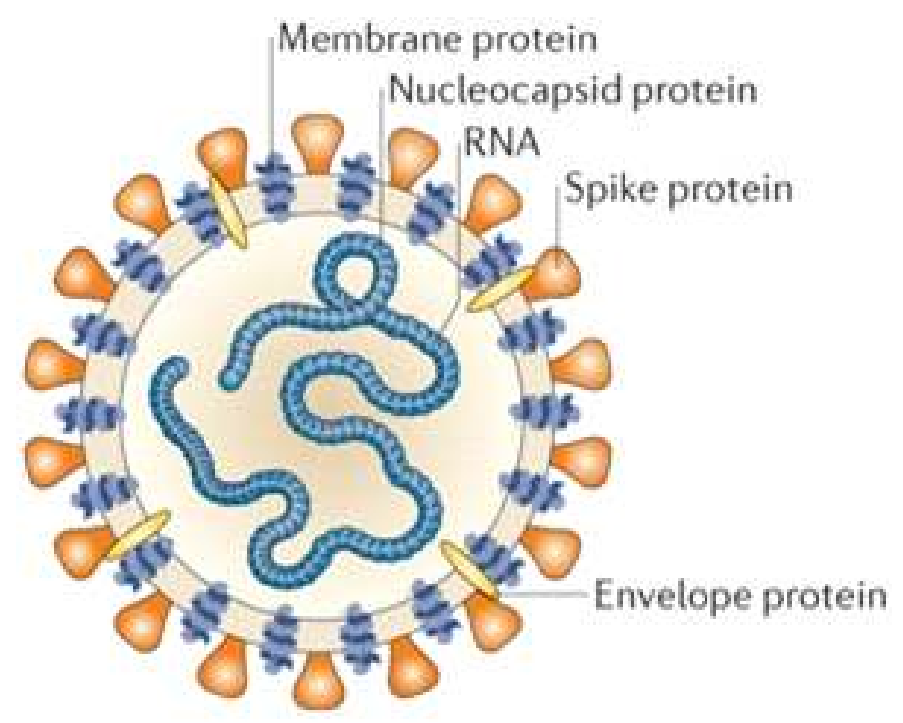

Figure 1: The genome structure of a coronavirus.

\section{Ancestries of infection}

Before the discovery of SCOV (SARS coronavirus), Coronaviridae family members were classified into three main phylogenetic groups. According to phylogenetic analyses existing groups of CoV do not include SCoV as a member of their groups but later studies suggested that SCoV and other groups might have common early and reserved heritage. ${ }^{21,22}$ In wet market small mammals like civets were found as a source of SCoV. Strikingly, extensive animal surveys discovered that $\mathrm{CoV}$ in bats showed high levels of genomic diversity. A cluster of Covs known as SARS-like CoVs (SLCoVs) recognized from bats also shares $88-92 \%$ genome homology with SCoV. These outcomes direct to the fact that bats are the expected reservoir of SARS$\mathrm{CoV}$ as well as further members of Coronaviridae family. $^{23,24}$

Further analysis proposed that novel corona virus COVID-19 have a nearby evolutionary relationship with SARS like bat coronaviruses RaTG13 (GenBank No.: MN996532) through nucleotide similarity which is 96.2 percent in the entire genome. These findings are also confirmed in a study that novel corona virus has strictly homology with RaTG13, a bat coronavirus isolate. ${ }^{25}$ Paraskevis and his coworker's findings support their hypothesis that there is genetic similarity between bat and 2019-nCoV but it does not provide the particular variant that is responsible for the outbreak in humans. ${ }^{18}$ Additional groups recommend that mink, turtle, snake and pangolin might be potential host for virus. ${ }^{26,27}$ which still require more confirmations to be established.

\section{Covid-19 and former Coronaviruses Distribution and} Environmental resistance

The Covid-19 virus resistance against humidity and temperature is not clear. Conversely, in case of SARS viruses type specific members of the Coronaviridae family has found to be resistant against moisture and cold. $^{28,29}$ At normal conditions of humidity and temperature the SARS virus is found to be resistant till 5 days. But multiplication speed is slowed down at humidity more than $95 \%$ and temperatures more than $38^{\circ} \mathrm{C}$. On the other hand in low temperatures and low humidity its resistance is comparatively high, that is the reason they may multiply and spread easily in subtropical areas counting Hong Kong and China. SARS survival in human specimens has been stated very high which specifies its extreme resistance against challenging environments. However, luckily the virus might be killed by high temperature more than $38^{\circ} \mathrm{C}$, acidic and alkaline $\mathrm{pH}$ and by using UV radiations. ${ }^{30}$ However, what makes Covid-19 remarkably different from others is its very great speed of transmission and perhaps its environmental resistance. In another study, it was reported that unlike SARS, Covid-19 patients had high-grade viral load in the early stages of the disease, which could be due to its severity and epidemic. ${ }^{31}$

\section{Phylogenetic analysis and evolutionary relationship of COVID-19}

Genetic diversity and evolution of viruses is mainly due to nucleotide exchange. ${ }^{32}$ Hereditary examinations of eighty-six complete or near to entire genomes of SARSCoV-2 revealed numerous mutations and omissions on coding and non-coding sections. These perceptions gave proof of the evolutionary changes and quick development of this novel coronavirus. ${ }^{33}$ Although the 
genomes of COVID-19 is less likely to be variable. Ceraolo and Giorgi, 2020 set out an analysis to investigate potential hypervariable hotspots among the viral population. Multiple sequence alignment carried out on 54 complete COVID-19 genome and come up with the findings that genomic arrangements of 2019nCoV were same as that of SARS.

Phylogenetic investigations assisted the scientists to more readily recognize the spread chains and follow the origins of viral pandemics, which give significant data to making general health strategy. In a recent study carried out by Lu and his fellows in 2020 supported the facts that COVID-19 was closely identical to two bat derived sequences of coronaviruses as, bat-SLCoVZXC21 and bat-SL-CoVZC $45 .{ }^{17}$ They studied ten genome sequences of novel corona virus COVID-19 that were obtained from nine CoV patients and observed 99.98\% nucleotide resemblance of obtained novel COVID-19 genomes sequences with Severe acute respiratory syndrome like coronaviruses but these genomes sequences were found to be $79 \%$ different from SARS-COV and about 50\% from MERS-CoV. Phylogenetic analysis discovered with the intention of COVID-19 which belongs to genus Beta coronavirus and subgenus sarbecovirus. Long branch length was nearest to bat-SL-CoVZXC21 or bat-SL-CoVZC45 but hereditarily differ as of SARS-COV. Particularly homology modelling showed to COVID-19 despite of amino acid substitution at some place, had a receptor binding sites that is similar to SARS-CoV. Their phylogenetic results reveals that bats could be the inventive potential host for this virus emergence and there is ample difference from SARS-CoV to be considered as a novel coronavirus that have humans to human transmission.

Many particulars propose that the animals may serve as a transitional host among bats or humans. Epidemic was earliest described in late December 2019, with bats being the most dormant species in Wuhan. The relatively longer branch length between 2019-nCoV and its close families shows less than 90\% identity which indicates that bat-SL-CoVZXC21 and bat-SL-CoVZC45 have no direct ancestry for novel corona virus. Fourthly bats remains natural reservoir for both MERS-CoV and SARS-COV with a different animal acting as an intermediate host like palm civet for SARS-CoV35 and dromedary camels for MERS-CoV. While humans work at the same time as a terminal host. Thus on the basis of recent outcomes it is most likely that bats might be the initial source of 2019-nCoV endemic in Wuhan or might be due to the wild animals that were available in seafood market in Wuhan. ${ }^{34}$
Based on whole genome evolutionary analysis, phylogenetic tree comprises of two clades. 2019- nCoV fall in the first clade. SARS-CoV, MERS-CoV and SARSlike bat CoV also share clade one while other genera including a coronavirus, $\gamma$ coronavirus, and $\delta$ coronavirus are found in the second clade of phylogenetic tree. 2019-nCoV runs comparable to the SARS-like bat CoVs whereas SARS-CoVs run down to the SARS-like bat CoVs. These findings indicates that in terms of whole genome sequencing 2019-nCoV resemble much more with SARS-like bat CoVs than SARS-CoVs. Phylogenetic analysis on the basis of proteins of matrix, envelop, accessory proteins, proteins of pp1a, pp1ab and nucleocapsid genes shows closest relationship among 2019-nCoV and SARS-like bat CoVs. While in stipulations of spike gene analysis 2019-nCoV is in close association to bat- CoVs. Accessory genes like $3 \mathrm{a}$ and $8 \mathrm{~b}$ are also nearby to the SARS-like bat CoVs. Evolutionary phylogenetic analysis clearly support the facts that 2019-nCoV is in close association to SARS-like bat COVID. ${ }^{35}$

In January 24, 2020, 26 viral genomes of 2019-nCoVs were known. Xiong and his fellows analyzed 24 whole genomes from these by excluding one (EPI_ISL_402125) having incomplete information and one (EPI_ISL_402125) with extremely short information and the coding sequence (CDS) of many important proteins mainly soluble enzymes of novel corona virus that play a crucial function in the infectious series of virus. ${ }^{36}$ A segregate (EPI_ISL_403928) was diverse from other 23 whole genomes that were being analyzed in respect of entire genome and the CDS of N, P and S. The evolutionary hierarchy trees represent that all sequesters of 2019-nCoVs spontaneously clustered on entire genome and CDS of $\mathrm{V}$ proteins, demonstrating their close relationship.

On the other hand, in the intact genome and the coding sequence (CDS) of $P, S$ and $N$, an isolate (EPI_ISL_403928) was different from other 23 proteins. They reported twenty two variations among EPI_ISL_403928 and rest of 2019-nCoVs. During their evolution process they also analyzed the replacement rate of nucleotide in the complete genome and some protein's CDS. Which ultimately results in the several amino acids substitution. They found that whole genome has the lowest rate of nucleotide substitution. Furthermore Ceraolo and his coworkers included 53 whole genome sequences of 2019 nCoV from database and observed maximum conservation between the tested genomes with $99 \%$ sequence identity. A bat CoV (Gisaid EPI_ISL_402131) genome exhibited 96.2 percent progression similarity or $99 \%$ query coverage with 
reference sequence $2019 \mathrm{nCoV}$ (NC_045512.2). The human SARS genome (NC_004718.3) observed most distant to the reference sequence 2019 nCoV as sequence identity was 80.26 percent and 98\% was query coverage. They aligned 70 coronaviruses sequences and concluded the evolutionary relationship. Despite the difference in sampling locations they reported that bootstrapped maximum likelihood tree reveal that all the human coronaviruses are very identical to each other.

\section{CONCLUSION}

Around the world, in most countries large numbers of peoples have been infected with Covid-19. Its transmission route is really obscure but rate of transmission is very high and complex. Covid -19 pandemic is not as much dangerous as that of AIDS and pandemics of last century. On the flip side, because of its high transfer speed, it does not let countries to use well-known methods of protection such as solitary confinement or basic health policies. Thus, it seems that natural factors such as herd protection against the replication of viruses in the human immune system will soon be able to balance their own decay and become more compatible with man. In summary its abvious that Genetic diversity and evolution of viruses is mainly due to nucleotide exchange. We have reviewd many studies that provide the evidence that the genomes of COVID19 are less likely to be variable. These observations will help the scientist in finding the prospects of effective treatment for this new virus. Phylogenetic analysis suggested that novel corona virus COVID-19 have a nearby evolutionary relationship with SARS like bat coronaviruses and bats could be the unique potential host for this virus emergence and is suitably different from SARS-CoV to be considered as a novel coronavirus that have human to human transmission. The particular genetic features of 2019-nCoV and their potential affiliation with virus traits and virulence in humans continue to be elucidated.

\section{Disclosure statement}

Authors account no conflict of interest regarding submitted work.

\section{REFERENCES}

1. Chan HL, Tsui SK, Sung JJ. Coronavirus in severe acute respiratory syndrome (SARS). Trends Mol Med 2003; 9:323-5. doi:10.1016/s1471-4914(03)00135-7.

2. Cui J, Li F, Shi ZL. Origin and evolution of pathogenic coronaviruses. Nat Rev Microbiol 2019; 17:181-92. doi:10.1038/s41579-018-0118-9.
3. Huang C, Wang Y, Li X, Ren L, Zhao J, Hu Y, et al. Clinical features of patients infected with 2019 novel coronavirus in Wuhan, China. Lancet 2020; 395:497506. doi:10.1016/S0140-6736(20)30183-5.

4. Wang X, Zhou Q, He Y, Liu L, Ma X, Wei X, et al. Nosocomial outbreak of COVID-19 pneumonia in Wuhan, China. Eur Respir J 2020; 55:2000544. doi:10.1183/13993003.00544-2020.

5. Z Zhu N, Zhang D, Wang W, Li X, Yang B, Song J, et al. A Novel Coronavirus from Patients with Pneumonia in China, 2019. N Engl J Med 2020; 382:727-33. doi:10.1056/NEJMoa2001017.

6. Yang Y, Xiao Z, Ye K, He X, Sun B, Qin Z, et al. SARS-CoV2: characteristics and current advances in research. Virol J 2020 29; 17:117. doi:10.1186/s12985-020-01369-z.

7. Special Expert Group for Control of the Epidemic of Novel Coronavirus Pneumonia of the Chinese Preventive Medicine Association. An update on the epidemiological characteristics of novel coronavirus pneumonia (COVID-19). Zhonghua Liu Xing Bing Xue Za Zhi 2020; 41:139-44.

doi:10.3760/cma.j.issn.0254-6450.2020.02.002.

8. Song Z, Xu Y, Bao L, Zhang L, Yu P, Qu Y, et al. From SARS to MERS, Thrusting Coronaviruses into the Spotlight. Viruses 2019;11:59. doi:10.3390/v11010059.

9. Guan Y, Zheng BJ, He YQ, Liu XL, Zhuang ZX, Cheung CL, et al. Isolation and characterization of viruses related to the SARS coronavirus from animals in southern China. Science 2003; 302:276-8.

doi:10.1126/science.1087139.

10. Drosten C, Kellam P, Memish ZA. Evidence for camel-tohuman transmission of MERS coronavirus. N Engl J Med 2014;371:1359-60.

doi:10.1056/NEJMc1409847.

11. Li F. Structure, Function, and Evolution of Coronavirus Spike Proteins. Annu Rev Virol 2016; 3:237-61. doi:10.1146/annurev-virology-110615-042301.

12. Tang Q, Song $\mathrm{Y}$, Shi $\mathrm{M}$, Cheng $\mathrm{Y}$, Zhang $\mathrm{W}$, Xia XQ. Inferring the hosts of coronavirus using dual statistical models based on nucleotide composition. Sci Rep 2015; 5:17155.

doi:10.1038/srep17155.

13. Ceraolo C, Giorgi FM. Genomic variance of the 2019-nCoV coronavirus. J Med Virol 2020; 92:522-8. doi:10.1002/jmv.25700.

14. Jiang S, Shi ZL. The First Disease X is Caused by a Highly Transmissible Acute Respiratory Syndrome Coronavirus. Virol Sin 2020; 35:263-5. doi:10.1007/s12250-020-00206-5

15. Lai CC, Shih TP, Ko WC, Tang HJ, Hsueh PR. Severe acute respiratory syndrome coronavirus 2 (SARS-CoV-2) and corona virus disease-2019 (COVID-19): the epidemic and the challenges. Int J Antimicrob Agents 2020; 55:924.

doi.org/10.1016/j.ijantimicag.2020.105924

16. Li C, Yang Y, Ren L. Genetic evolution analysis of 2019 novel coronavirus and coronavirus from other species. 
Infect Genet Evol 2020; 82:104285.

doi:10.1016/j.meegid.2020.104285.

17. Lu R, Zhao X, Li J, Niu P, Yang B, Wu H, et al. Genomic characterisation and epidemiology of 2019 novel coronavirus: implications for virus origins and receptor binding. Lancet 2020 22; 395:565-74.

doi:10.1016/S0140-6736(20)30251-8.

18. Paraskevis D, Kostaki EG, Magiorkinis G, Panayiotakopoulos G, Sourvinos G, Tsiodras S. Fullgenome evolutionary analysis of the novel corona virus (2019-nCoV) rejects the hypothesis of emergence as a result of a recent recombination event. Infect Genet Evol 2020; 79:104212.

doi:10.1016/j.meegid.2020.104212.

19. Zhu Z, Zhang Z, Chen W, Cai Z, Ge X, Zhu H, et al. Predicting the receptor-binding domain usage of the coronavirus based on kmer frequency on spike protein. Infect Genet Evol 2018; 61:183-4. doi:10.1016/j.meegid.2018.03.028.

20. Jeffers SA, Tusell SM, Gillim-Ross L, Hemmila EM, Achenbach JE, Babcock GJ, et al. CD209L (L-SIGN) is a receptor for severe acute respiratory syndrome coronavirus. Proc Natl Acad Sci USA 2004; 101:1574853. doi:10.1073/pnas.0403812101.

21. Snijder EJ, Bredenbeek PJ, Dobbe JC, Thiel V, Ziebuhr J, Poon LL, et al. Unique and conserved features of genome and proteome of SARS-coronavirus, an early split-off from the coronavirus group 2 lineage. J Mol Biol 2003; 331:991-1004. doi:10.1016/s0022-2836(03)00865-9.

22. Gorbalenya AE, Snijder EJ, Spaan WJ. Severe acute respiratory syndrome coronavirus phylogeny: toward consensus. J Virol 2004; 78:7863-6. doi:10.1128/JVI.78.15.7863-7866.2004.

23. Tang XC, Zhang JX, Zhang SY, Wang P, Fan XH, Li LF, et al. Prevalence and genetic diversity of coronaviruses in bats from China. J Virol 2006; 80:7481-90. doi:10.1128/JVI.00697-06.

24. Vijaykrishna D, Smith GJ, Zhang JX, Peiris JS, Chen H, Guan Y. Evolutionary insights into the ecology of coronaviruses. J Virol 2007; 81:4012-20. doi:10.1128/JVI.02605-06.

25. Liu Z, Xiao X, Wei X, Li J, Yang J, Tan H, et al. Composition and divergence of coronavirus spike proteins and host ACE2 receptors predict potential intermediate hosts of SARS-CoV-2. J Med Virol 2020; 92:595-601. doi:10.1002/jmv.25726.
26. Ji W, Wang W, Zhao X, Zai J, Li X. Cross-species transmission of the newly identified coronavirus 2019nCoV. J Med Virol 2020; 92:433-40. doi:10.1002/jmv.25682.

27. Li X, Zai J, Zhao Q, Nie Q, Li Y, Foley BT, et al. Evolutionary history, potential intermediate animal host, and cross-species analyses of SARS-CoV-2. J Med Virol 2020; 92:602-11. doi:10.1002/jmv.25731.

28. Geller C, Varbanov M, Duval RE. Human coronaviruses: insights into environmental resistance and its influence on the development of new antiseptic strategies. Viruses 2012; 4:3044-68.

doi:10.3390/v4113044.

29. Chan KH, Peiris JS, Lam SY, Poon LL, Yuen KY, Seto WH. The Effects of Temperature and Relative Humidity on the Viability of the SARS Coronavirus. Adv Virol 2011; 2011:734690. doi:10.1155/2011/734690.

30. Duan SM, Zhao XS, Wen RF, Huang JJ, Pi GH, Zhang SX, et al. Stability of SARS coronavirus in human specimens and environment and its sensitivity to heating and UV irradiation. Biomed Environ Sci 2003; 16:246-55.

31. Darnell ME, Subbarao K, Feinstone SM, Taylor DR. Inactivation of the coronavirus that induces severe acute respiratory syndrome, SARS-CoV. J Virol Methods 2004; 121:85-91.

doi:10.1016/j.jviromet.2004.06.006.

32. Lauring AS, Andino R. Quasispecies theory and the behavior of RNA viruses. PLoS Pathog 2010; 6:e1001005. doi:10.1371/journal.ppat.1001005.

33. Phan T. Genetic diversity and evolution of SARS-CoV-2. Infect Genet Evol 2020;81:104260. doi:10.1016/j.meegid.2020.104260.

34. Alagaili AN, Briese T, Mishra N, Kapoor V, Sameroff SC, Burbelo PD, et al. Middle East respiratory syndrome coronavirus infection in dromedary camels in Saudi A rabia.m Bio $2014 ; 5$ : e 00884 -14. doi:10.1128/mBio.00884-14.

35. Wu A, Peng $Y$, Huang $B$, Ding $X$, Wang $X$, Niu $P$, et al. Genome Composition and Divergence of the Novel Coronavirus (2019-nCoV) Originating in China. Cell Host Microbe 2020; 27:325-8.

doi:10.1016/j.chom.2020.02.001.

36. Dimonte S, Babakir-Mina M, Hama-Soor T, Ali S. Genetic Variation and Evolution of the 2019 Novel Coronavirus. Public Health Genomics 2021; 24:54-66 doi:10.1159/000513530. 